\title{
Dynamic interface model for masonry walls subjected to high strain rate out-of-plane loads
}

\author{
S. Hashemi Rafsanjani ${ }^{a, 1}$, P.B. Lourenço ${ }^{a, 2}$, N. Peixinho ${ }^{\text {b,3 }}$ \\ a'ISISE, University of Minho, Department of Civil Engineering, Azurém, 4800-058 \\ Guimarães, Portugal \\ bCT2M, University of Minho, Department of Mechanical Engineering, Azurém, 4800- \\ 058 Guimarães, Portugal
}

${ }^{1}$ (Corresponding author) PhD Candidate, ISISE, University of Minho, Department of Civil Engineering, Azurém, 4800-058 Guimarães, Portugal. Tel.: +351 910775 946; fax: +351 253510 217. E-mail: b6000@civil.uminho.pt

${ }^{2}$ Professor, ISISE, University of Minho, Department of Civil Engineering, Azurém, 4800-058 Guimarães, Portugal. Tel.: +351 253510 209; fax: +351 253510 217. E-mail: pbl@civil.uminho.pt

3 Assistant Professor, CT2M, University of Minho, Department of Mechanical Engineering, Azurém, 4800-058 Guimarães, Portugal. Tel.: +351 253510 220; fax: +351 253516 007. E-mail: Peixinho@dem.uminho.pt 


\begin{abstract}
The present study proposes a dynamic constitutive material interface model that includes non-associated flow rule and high strain rate effects, implemented in the finite element code ABAQUS as a user subroutine. First, the model capability is validated with numerical simulations of unreinforced block work masonry walls subjected to low velocity impact. The results obtained are compared with field test data and good agreement is found. Subsequently, a comprehensive parametric analysis is accomplished with different joint tensile strengths and cohesion, and wall thickness to evaluate the effect of the parameter variations on the impact response of masonry walls.
\end{abstract}

Key words: Block work masonry wall; high strain rate loading; interface model; out-of-plane behavior; dynamic Increase factor

\title{
1 Introduction
}

Masonry is a highly durable form of construction, widely used to build load bearing and partition walls in modern structures. Masonry is also used in many historical buildings and monumental structures. Until Oklahoma City bombing in 1995, studies dealing with the blast behavior of structures were a field of limited interest in the civil engineering community. After this terrorist incident, a great deal of effort has been done to devise solutions to reduce destructive damages and casualties due to such devastative loads. Beyond doubt, masonry structures are usually vulnerable to explosive blast loads. In this regard, conducting experiments and validating numerical models with field test data leads to a better understanding of the blast response of masonry walls and the relevance of the different masonry material properties, which, consequently, results in innovation of strengthening techniques and of assessment and design methods. 
A series of experimental studies in masonry panels and structures has been carried out to report their blast response, including maximum deflection and failure mechanisms of collapse, and to evaluate their performance. Varma et al. [1] provided the maximum deflection, the damage level, the reflected pressure, and the reflected impulse of 27 full scale tests with different thickness on brick panels subjected to blast loading. Evaluation of structural masonry damage and fragmentation of non-retrofitted masonry walls has also been of interest in a number of studies. The formation of cracks in horizontal mortar joints, and bond failure at the joint with overturning about mid-height were reported as most likely dominant failure mechanisms of unreinforced masonry walls with concrete masonry units (CMU) by Baylot et al. [2] and Dennis, Baylot, and Woodson [3], respectively. The crack patterns of unreinforced masonry walls were classified into two groups based on the time of formation in Gilbert, Hobbs, and Molyneaux [4]. These walls were subjected to low velocity impacts. Eamon, Baylot, and O'Daniel [5] classified the CMU wall behavior against blast loads into three categories, using different ranges of pressure magnitude namely high, moderate and low.

It is noted that the majority of existing structures were not designed with blast loading in mind. Hence, despite the large costs usually involved in laboratory tests, various retrofitting techniques have been evaluated to find effective techniques to improve the blast resistance of existing structures, aiming at the reduction of casualties and losses. Baylot et al. [2] adopted three different retrofitting methods, namely bonding FRP, applying sprayed-on polyurea and placing a sheet of steel on the back of the wall, to improve the blast response of CMU walls. Muszynski and Purcell [6] carried out tests on retrofitted concrete masonry walls with CFRP, technique which led to a remarkable reduction in displacement. Davidson et al. [7] reported also the application of a sprayed-on polymer retrofit for strengthening masonry walls against blast loads. 
Due to the costs of laboratory tests, it is impossible to carry out a large number of tests. This would allow obtaining a comprehensive field test database, including most likely responses. Currently, given the development of computer technology, it is easy to have more detailed and accurate predictions, including dynamic response and localized damage through numerical simulations. Two common strategies have been developed for numerical simulation of masonry in the literature, namely micro strategy and macro strategy, see e.g. Lourenço [8] . Using the micro approach, a more accurate representation of the behavior of a masonry structure is usually obtained with detailed failure mechanisms of the components, while, in a macro approach, the global behavior of the structures is usually of more concern. Within, the macro approach, homogenization techniques incorporate the geometry at microlevel and became rather popular in the last decades, see Lourenço et al. [9] for a review. Depending upon the required accuracy, reliability, availability and computational costs, one of the approaches can be selected.

Recently, a numbers of investigations have been performed to identify and determine relevant parameters for blast response of masonry walls. A parametric study was conducted by Wei and Stewart [10] to study the influence of mortar and brick strength, boundary conditions and wall thickness on response of the wall. As expected, increasing the mortar or brick strength decreases the maximum deflection of the wall. Also, an increase in the number of the fixed edges or wall thickness causes a reduction in the maximum deflection of the wall. A sensitivity analysis for CMU walls was considered in a study by Eamon [11]. Here, a chart was presented to identify variables significantly affecting the wall behavior at three different hazard levels.

In present paper, a newly developed dynamic interface model accounting for strain rate effects is proposed for numerical simulations of the structural response of masonry walls subjected to low velocity impact using the finite element (FE) code ABAQUS. The rate- 
dependent failure envelop is divided into three parts, namely tension mode, coulomb friction mode, and compressive cap mode on the basis of the corresponding failure mechanisms. After implementing the material model into ABAQUS as a user subroutine, a micro approach is used for numerical modeling of masonry walls. The developed model is attributed to interface elements to simulate the mortar behavior between two boundaries. A comparison between numerical results and field test data obtained by Gilbert et al. [4] is performed to evaluate the performance of the proposed material model and the accuracy of the simulation in predicting the impact response and damage of masonry walls. Finally, a parametric study is carried out to discuss the effectiveness of the main parameters changes on the global behavior of masonry walls.

\section{A plastic interface model for high strain rates}

In recent years, a number of investigations has been conducted to evaluate the high strain rates effects and to derive constitutive models for different materials subjected to high strain rate loading. A plastic damage material model was utilized to characterize the brick and mortar behavior in micro numerical simulation of blast response of unreinforced walls by Wei and Stewart [10]. The damage dependent piecewise Drucker-Prager strength criterion was involved for continuum modeling of brick and mortar. No interface behavior was considered in the analysis. A simple rigid-perfectly plastic homogenization masonry model was developed by Milani, Lourenço, and Tralli [12] for micro numerical simulation of masonry structures subjected to out-of plane high strain rate loads. The proposed model is characterized by a low number of input material parameters, and also by being numerically inexpensive and robust. The aforementioned model was assigned to a FE thin plate triangular element. A Drucker-Prager with a cap failure criterion was adopted for bricks and joints subdomains, and a Mohr-Coulomb failure criterion with compressive linearized cap and tension 
cut-off was utilized for bricks-joints interfaces. For the macro numerical prediction of blast response and damage of masonry panels, Wei and Hao [13] introduced a continuum damage model with strain rate effects based on homogenization techniques. The proposed failure envelop can be defined at different strain rate levels and is divided into four parts. A compressive cap was considered due to masonry failure under tri-axial compression.

In the present study, a rate dependent interface model is introduced to characterize the mortar behavior. Depending upon the main failure mechanisms of masonry walls, the failure envelop is divided into three parts namely, tension cut-off, Coulomb friction, and elliptical cap, see Fig. 1. Hence, each part has its own failure criterion presented in terms of $k$, where the $k$ parameter is a scalar involved to measure the amount of softening and hardening in order to control the yield surface, and in terms of the stress $\boldsymbol{\sigma}$. For a 3D configuration, $\boldsymbol{\sigma}=\left\{\sigma, \tau_{s}, \tau_{t}\right\}^{T}$ , $D=\operatorname{diag}\left\{k_{n}, k_{s}, k_{t}\right\}$ and $\varepsilon=\left\{\Delta u_{n}, \Delta u_{s}, \Delta u_{t}\right\}^{T}$. The subscripts $n, s, t$ denote the normal and two perpendicular shear components.

In order to consider the high strain rate effects on the interface material model, a few number of dynamic increase factors (DIFs) are defined to control the failure envelop. The DIF is the ratio between the dynamic and static parameters' values. These factors multiply the material parameters to expand or to contract the failure envelope at different strain rate levels.

For the tension cut-off mode, the yield function is given as follows

$$
f_{1}\left(\sigma, k_{1}\right)=\sigma-\bar{\sigma}_{1}\left(k_{1}\right)
$$

where $\sigma$ denotes the normal stress and $k_{1}$ denotes a scalar to measure the amount of softening. For the hardening/softening behavior the yield stress value $\bar{\sigma}_{1}$ varies exponentially as 


$$
\bar{\sigma}_{1}=f_{t} \exp \left(-\frac{f_{t}}{G_{f}^{I}} k_{1}\right)
$$

Here, $f_{t}$ is the tensile strength of the joint (usually equal to the unit-mortar interface) and $G_{f}^{I}$ is the mode I fracture energy.

The dynamic increase factors are applied to the uniaxial tensile strength and the fracture energy to obtain

$$
\begin{gathered}
f_{t}=D I F \times f_{t_{0}} \\
G_{f}^{I}=D I F \times G_{f_{0}}^{I}
\end{gathered}
$$

where, $f_{t_{0}}$ and $G_{f_{0}}^{I}$ are the quasi-static strength and fracture energy under uniaxial tension, respectively.

In the case of strain hardening, the scalar $\dot{k}_{1}$ is given, in rate form, as

$$
\dot{k}_{i}=\sqrt{\left(\dot{\varepsilon}_{i}^{p}\right)^{T} \dot{\varepsilon}_{i}^{p}}
$$

where the plastic strain rate $\dot{\varepsilon}_{i}^{p}=\dot{\lambda}_{i} \frac{\partial g_{i}}{\partial \sigma}$.

Here, $g_{i}$ is the plastic potential and $\dot{\lambda}_{i}$ is the plastic multiplier. As in mode I the normal plastic relative displacement governs the softening behavior, the $\dot{k}_{1}$ can be assumed equal to

$$
\dot{k}_{1}=\left|\Delta \dot{u}_{n}^{p}\right|=\dot{\lambda}_{1}
$$

When yielding occurs, the plastic corrector brings back the stress update to the yield surface by applying locally a Newton-Raphson method to solve the nonlinear system and updating the stress tensor and the user-defined state variables. In a plasticity model, it is worth to mention that at the starting point the stress is assumed to be elastic (considering a trial value), 
such as $\sigma_{n+1}=\sigma^{\text {trial }}, \dot{k}_{n+1}=0$, and $\dot{\lambda}_{n+1}=0$, which is obtained by the elastic predictor. The unknowns of the nonlinear system of equations that arise in this update procedure are the stress components, $\dot{k}_{n+1}$ and $\dot{\lambda}_{n+1}$. The stress update equations are given for a finite step are given by

$\boldsymbol{\sigma}_{\mathrm{n}+1}=\boldsymbol{\sigma}^{\text {trial }}-D \dot{\varepsilon}_{n+1}^{p}$

with $\boldsymbol{\sigma}^{\text {trial }}=\boldsymbol{\sigma}_{\mathrm{n}}+D \dot{\varepsilon}_{n+1}$. The stress update equations can be easily obtained from the set of non-linear equations system

$\left\{\begin{array}{l}\sigma_{n+1}=\sigma^{\text {trial }}-\dot{\lambda}_{1, n+1} k_{n} \\ \tau_{n+1}=\tau^{\text {trial }}\end{array}\right.$

where $\tau=\sqrt{\tau_{s}^{2}+\tau_{t}^{2}}$ is assumed for 3D configuration. The derivative with respect to $\Delta \lambda_{n+1}$ is needed for the iterative local Newton-Raphson method, given by

$\left.\frac{\partial f_{1}}{\partial \dot{\lambda}_{1}}\right|_{n+1}=-k_{n}-\frac{\partial \bar{\sigma}_{1}}{\partial k_{1}}$

In mode II, the Coulomb friction yield criterion reads

$f_{2}\left(\sigma, k_{2}\right)=\tau+\sigma \tan \varphi\left(k_{2}\right)-\bar{\sigma}_{2}$

Here, $\tau$ and $\bar{\sigma}_{2}$ are given

$$
\begin{aligned}
& \tau=\sqrt{\tau_{s}^{2}+\tau_{t}^{2}} \\
& \bar{\sigma}_{2}=c \exp \left(-\frac{c}{G_{f}^{I I}} k_{2}\right)
\end{aligned}
$$

where, $c$ denotes the cohesion of the unit-mortar interface, $G_{f}^{I I}$ is fracture energy in mode II, and $\phi$ denotes the friction angle. 
The dynamic increase factors are applied to the cohesion, and mode II fracture energy and read

$c=D I F \times c_{0}$

$G_{f}^{I I}=D I F \times G_{f_{0}}^{I I}$

Again, here, $c_{0}$ and $G_{f_{0}}^{I I}$ are the quasi-static cohesion and fracture energy under shear, respectively.

A non-associated plastic potential $g_{2}$ is defined as

$g_{2}=\tau+\sigma \tan \psi-c$

Here, $\tan \psi$ is the dilatancy angle. In terms of pure shear, the shear plastic relative displacement can be assumed to control the softening behavior as

$$
\dot{k}_{2}=\left|\Delta \dot{u}_{s}^{p}\right|=\dot{\lambda}_{2}
$$

Manipulating the stress update equations, it is possible to obtain

$$
\left\{\begin{array}{l}
\sigma_{n+1}=\sigma^{\text {trial }}-\dot{\lambda}_{2, n+1} k_{n} \tan \psi \\
\tau_{n+1}=\tau^{\text {trial }}-\dot{\lambda}_{2, n+1} k_{s} \frac{\tau^{\text {trial }}}{\left|\tau^{\text {trial }}\right|}
\end{array}\right.
$$

The derivative required for the iterative local Newton-Raphson method is given by

$$
\left.\frac{\partial f_{2}}{\partial \dot{\lambda}_{2}}\right|_{n+1}=-k_{n} \tan \phi \tan \psi-k_{s}-\frac{\partial \bar{\sigma}_{2}}{\partial k_{2}}
$$

For the compressive cap mode, the yield function can be better provided in matrix notation form as

$$
f_{3}\left(\sigma, k_{3}\right)=\frac{1}{2} \sigma^{T} P \sigma+p^{T} \sigma-\left(\bar{\sigma}_{3}\left(k_{3}\right)\right)^{2}
$$


where $P$ is the projection matrix, given by $\operatorname{diag}\left\{2 C_{n n}, 2 C_{s s}\right\}$, and $p$ is the projection vector, given by $\left\{C_{n}, 0\right\}^{T}$. Here, $C_{n n}$ and $C_{n}$ are material parameters that determine the contribution of each stress component to failure, assumed equal to 1 and 0 , respectively (this provides a centered ellipsoid in the origin). Parameter $C_{s s}$ governs the intersection of the ellipsoid with the shear stress axis so that the maximum shear stress $\tau_{u}$ is given by $\tau_{u}=\frac{f_{m}}{\sqrt{C_{s s}}}$, where $f_{m}$ denotes the masonry compressive strength. It is recommended equal to 9, Lourenço [8].

The following law is used to introduce the hardening/softening behavior of masonry under uniaxial compression:

$$
\begin{aligned}
& \bar{\sigma}_{a}\left(k_{3}\right)=\bar{\sigma}_{i}+\left(\bar{\sigma}_{p}-\bar{\sigma}_{i}\right) \sqrt{\frac{2 k_{3}}{k_{p}}-\frac{k_{3}^{2}}{k_{p}^{2}}} \\
& \bar{\sigma}_{b}\left(k_{3}\right)=\bar{\sigma}_{p}+\left(\bar{\sigma}_{m}-\bar{\sigma}_{p}\right)\left(\frac{k_{3}-k_{p}}{k_{m}-k_{p}}\right)^{2} \\
& \bar{\sigma}_{c}\left(k_{3}\right)=\bar{\sigma}_{r}+\left(\bar{\sigma}_{m}-\bar{\sigma}_{r}\right) \exp \left(m \frac{k_{3}-k_{m}}{\bar{\sigma}_{m}-\bar{\sigma}_{r}}\right) \\
& \text { with } m=2 \frac{\bar{\sigma}_{m}-\bar{\sigma}_{p}}{k_{m}-k_{p}} .
\end{aligned}
$$

Here, the subscripts I, m, p and $\mathrm{r}$ in the yield value and scalar $\mathrm{k}$ indicate the initial, medium, peak and residual values, respectively, providing parabolic hardening, followed by exponential softening, see Fig. 2.

The dynamic increase factors of uniaxial compressive strength and hardening are utilized to shift the failure envelop at different strain rates.

$$
f_{m}=D I F \times f_{m_{0}}
$$




$$
k_{m}=D I F \times k_{m_{0}}
$$

$k_{p}=D I F \times k_{p_{0}}$

Here, $f_{m_{0}}, k_{p_{0}}$, and $k_{m_{0}}$ are quasi-static strength, amount of hardening corresponding to uniaxial compressive strength and scalars defining the inelastic law.

Considering an associated flow rule and strain hardening/softening hypothesis, Eq. (5) leads to

$$
\dot{k}_{3}=\dot{\lambda}_{3} \sqrt{(P \sigma+p)^{T}(P \sigma+p)}
$$

After manipulation, Lourenço [8], the stress update equation yields

$$
\sigma_{n+1}=\left(D^{-1}+\Delta \lambda_{3, n+1} P\right)^{-1}\left(\varepsilon_{\text {trial }}^{e}-\Delta \lambda_{3, n+1} p\right)
$$

with $\varepsilon_{\text {trial }}^{e}=D^{-1} \sigma^{\text {trial }}$.

The derivative necessary for iterative local Newton-Raphson method is given

$$
\left.\frac{\partial f_{3}}{\partial \Delta \lambda_{3}}\right|_{n+1}=\left(\frac{\partial f_{3}}{\partial \sigma}+\frac{\partial f_{3}}{\partial k_{3}} \frac{\partial k_{3}}{\partial \sigma}\right)^{T} \frac{\partial \sigma}{\partial \Delta \lambda_{3}}-h_{3}
$$

Where,

$$
\begin{array}{ll}
\frac{\partial f_{3}}{\partial \sigma}=P \sigma_{n+1}+p & \frac{\partial k_{3}}{\partial \sigma}=\Delta \lambda_{3, n+1} \frac{P\left(P \sigma_{n+1}+p\right)}{\sqrt{\left(P \sigma_{n+1}+p\right)^{T}\left(P \sigma_{n+1}+p\right)}} \\
\frac{\partial f_{3}}{\partial k_{3}}=-2 \bar{\sigma}_{3, n+1} \frac{\partial \bar{\sigma}_{3}}{\partial k_{3}} & \frac{\partial \sigma}{\partial \Delta \lambda_{3}}=-\left(D^{-1}+\Delta \lambda_{3, n+1} P\right)^{-1}\left(P \sigma_{n+1}+p\right) \\
h_{3}=-\frac{\partial f_{3}}{\partial k_{3}} \sqrt{\left(P \sigma_{n+1}+p\right)^{T}\left(P \sigma_{n+1}+p\right)}
\end{array}
$$

A series of experiments have been carried out to characterize the material properties of brick and mortar at high strain rates, resulted in derivation of DIFs. Hao and Tarasov [14] conducted a series of dynamic uniaxial compressive tests on brick and mortar using a tri-axial 
static-dynamic testing machine, providing the following DIFs for the material parameters at a specific range of strain rate. These tests provided the following equations:

(1) DIF of mortar

Regression equations for the ultimate compressive strength

$$
\begin{array}{llll}
D I F & =0.0372 \ln \dot{\varepsilon}+1.4025 & \text { for } & \dot{\varepsilon} \leq 13 s^{-1} \\
D I F & =0.3447 \ln \dot{\varepsilon}+0.5987 & \text { for } & \dot{\varepsilon}>13 s^{-1}
\end{array}
$$

Regression equation for the strain at ultimate compressive strength

$$
D I F=0.1523 \ln \dot{\varepsilon}+2.6479
$$

Regression equation for Young’s modulus

$$
D I F=0.7601-0.02272 \ln \dot{\varepsilon}
$$

(2) DIF of brick

Regression equations for the ultimate compressive strength

$$
\begin{array}{llll}
D I F=0.0268 \ln \dot{\varepsilon}+1.3504 & \text { for } & \dot{\varepsilon} \leq 3.2 \mathrm{~s}^{-1} \\
D I F=0.2405 \ln \dot{\varepsilon}+1.1041 & \text { for } & \dot{\varepsilon}>3.2 \mathrm{~s}^{-1}
\end{array}
$$

Regression equation for the strain at ultimate compressive strength

$$
D I F=0.0067 \ln \dot{\varepsilon}+1.0876
$$

Regression equations for the Young's modulus

$$
\begin{aligned}
& D I F=0.0013 \ln \dot{\varepsilon}+1.0174 \quad \text { for } \quad \dot{\varepsilon} \leq 7.3 s^{-1} \\
& D I F=0.3079 \ln \dot{\varepsilon}+0.4063 \quad \text { for } \quad \dot{\varepsilon}>7.3 s^{-1}
\end{aligned}
$$

Regression equations for the Poisson's ratio

$$
D I F=0.0085 \ln \dot{\varepsilon}+1.1112
$$


No information has been reported concerned to strain rate effects on tensile and shear material properties of masonry. Hence, the DIF for material properties in tension, shear and compression is assumed here. The behavior of the model under varying strain rate is fully demonstrated in the next section.

For the implementation of the proposed dynamic interface model in ABAQUS, a FORTRAN 77 user-subroutine was developed. Through this process, the material model is introduced by a failure criterion and the adopted Euler backward algorithm (linear predictor-plastic corrector approach) in the stress update process. The user-subroutine VUINTER provided in ABAQUS is involved to define contact interface behavior. The interface material is assumed to be bonded to each of two contacting surfaces (slave and master surfaces).

\section{Behavior of the model with different strain rates}

In order to illustrate the response of the developed material model in the prediction of joint behavior and appropriate implementation of user-defined subroutine in ABAQUS, simple numerical models of a rigid block were developed and submitted under uniaxial tension, pure shear, and uniaxial compression at different strain rate levels. The numerical models and the behavior subjected to each type of loading are given in Fig. 3 to Fig. 6. The typical material properties are adopted for the joints, and the dynamic increase factors proposed by Hao and Tarasov [14] are used here, see Table 1 . Here, $K_{n}$ is modulus of elasticity and $K_{s}$ is shear modulus.

Comparing the default material properties, introduced as input parameters to the software, and the numerical mortar behavior at different strain rate levels, full agreement between both is noticed. Hence, the material model and implementation in the user-subroutine in FE code ABAQUS seems to be adequate. 


\section{Numerical simulation and comparison with experimental results}

The experimental data by Gilbert et al. [4] is used for validation of the developed numerical model. In their study, 21 full-scale unreinforced walls, made of bricks and blocks bonded by mortar layers at bed and head joints, were subjected to low velocity impacts with different applied impulses applied by square steel plate placed at mid-length. Two walls, namely URW1 andURW 2 are considered here. These walls have clear size of $5.75 \times 1.15 \mathrm{~m}$ and $9.15 \times 1.13 \mathrm{~m}$, using mortar bonded concrete blockwork with dimensions of $440 \times 215 \times 200 \mathrm{~mm}$ and $440 \times 215 \times 215 \mathrm{~mm}$, and are constructed for two different thicknesses of $200 \mathrm{~mm}$ and $215 \mathrm{~mm}$, respectively. The mortar type was kept constant in both tests. The walls were placed on $12 \mathrm{~mm}$ thick steel plates bolted to the strong floor and jointed to the walls using epoxy. Two stiff concrete blocks served as abutments and were constructed at the extremes of the walls. The abutments were connected to the walls using epoxy mortar, precluding the rotation at edges. It was noted that these types of bonding produce fixed boundary condition at three edges. According to the field test results, no serious damage was seen in both abutments, so they are assumed as rigid boundaries in numerical simulation. The impact load was applied through a $400 \times 400 \times 50 \mathrm{~mm}^{3}$ steel plate at mid-height of the wall. The details of the walls and dimensions are shown in Fig. 7. In numerical modelling, the applied load is modelled by a triangular load-time distribution with peak force of $90 \mathrm{KN}$ and $110 \mathrm{KN}$ reaches at $22.9 \mathrm{msec}$ and $25 \mathrm{msec}$, respectively, see Fig. 8.

The dynamic interface model is attributed to 3D interface elements to take into account the joint behavior during numerical simulation. Since the failure mechanisms of masonry walls subjected to high strain rate loads mostly deal with failure in joints, no serious damage is expected for the units and they were considered elastic and modeled by 3D solid elements. 
The finite element meshes of the wall URP1 is given in Fig. 9. As shown, a fine mesh was adopted for the concrete block units. Since no field test data was reported on tensile material properties of mortar, the previously given tensile material properties are adopted for the joints. The material properties of the blocks, joints and their corresponding dynamic increase factors, Hao and Tarasov [14], are presented in Table 2 and Table 3. It is noted that the tensile strength of masonry can vary significantly according to the materials adopted (unit and mortar), and for this reason a parametric analysis is carried out later in the paper. As an example, the European Norm EN 1996-1-1:2005 provides values for the flexural strength of masonry ranging from 0.05 to $0.20 \mathrm{MPa}$. A comparison between the predicted wall response and field test data is carried out using crack patterns and deflection, to evaluate the accuracy of the predictions. Fig. 10 and Fig. 11 show the observed crack patterns of the both tested parapets, URP1 and URP2 subjected to out of plane impact loads. The deformations of the parapets recorded at the maximum deflections are presented in Fig. 12 and Fig. 13. According to predictions, it is noted that vertical cracks were formed over entire height of the parapet URP1 at the center and to each side, and both right and left parts rotated inside. Moreover, the cracks are distributed along the length of the parapet, see Fig. 12. For the wall URP2, besides a vertical fracture line occurred at the center over the entire height of the wall, diagonal fractures, distributed around the centerline in both sides, were observed connected to horizontal cracks, see Fig. 13. Some horizontal cracks are noticed in joints at lower levels. It is evident that increasing the length of the wall, reduces the effect of the boundaries and cracks localize close to the impact zone. An appropriate agreement in prediction of failure modes is apparent between the tests and simulations.

Next, a comparison is made for the displacement vs. time response of the walls. The displacements are recorded at the points located at mid-height and $580 \mathrm{~mm}$ above the base, offset by $500 \mathrm{~mm}$ and $250 \mathrm{~mm}$ to the left of the centerline, respectively. As shown in Fig. 14, 
the numerical models can predict the high strain rate response of the walls including magnitude of peak displacement and post-peak trend close to the observed test results. Here it is noted that for wall URP1 there is a pronounced built up of stiffness found in response due to the inertial forces and acceleration of movement. For the wall URP2, The numerical response is shifted to the origin because the experiment does not show the initial acceleration of movement.

\section{$5 \quad$ Parametric studies}

The wall URP1, shown in the previous section is now adopted in parametric studies to investigate the influence of the variation of the parameters, namely material properties of the joint and wall thickness, on the high strain rate response of masonry walls. The effects of the parameters are evaluated by comparing the maximum deflections and crack patterns with the reference (experimental) response.

\subsection{Influence of material properties}

Three types of tensile strength, cohesion, and dilatancy angle are used distinctly to investigate the effectiveness of material properties of the joint, as summarized in Table 4. Only one parameter is changed for each analysis, using Type 2 values as reference values. The displacement-time responses of the masonry wall for three types of tensile strength and three types of cohesion are presented in Fig. 15 and Fig. 16, respectively.

Comparing the above diagrams for the masonry wall with three types of tensile strengths and cohesions, it is noted that reducing the tensile strength or cohesion leads to an increase in deflection of the wall up to 2.3 and 1.4 times, respectively. The effect of tensile strength is much larger than the cohesion for this wall. No changes could be found in the damage mechanism, so the results are not shown. 
The dilatancy angle takes into account the uplift when a unit slides over the other units Dilatancy produces a vertical displacement (if the structure is unrestrained) or a normal stress built-up (if the structure is restrained). The dilatancy angle degrades with the normal confining pressure and plastic shear slipping increases. For practical purposes, it is recommend to adopt a zero value, Lourenço [8], in order to avoid locking in restrained quasistatic calculations. Fig. 17 shows the displacement-time responses of the masonry wall with three types of dilatancy angles subjected to low velocity impact. It is observed that when the dilatancy angle changes from 0.2 to zero, the deflection of the wall increases 1.75 times so that it can be concluded that the influence of the dilatancy on deflection is extremely large for high strain rate loading, even for the relatively unconfined wall shown. It is of interest to mention that the failure mode also changes. As shown in Fig. 18, when the dilatancy angle tends to zero, shear slipping grows considerably with a much more localized failure mode. For a (small) non-zero dilatancy angle, a more homogeneous response of the wall is found.

\subsection{Influence of wall thickness}

Fig. 19 shows the displacement-time diagrams of the masonry wall with three wall thicknesses. The reference material properties of mortar and block are applied in the three walls. The numerical results indicate that the wall with wall thickness $200 \mathrm{~mm}$ has the maximum deflection, as expected. The growth of deflection is almost 2.3 times with the decrease of the wall thickness. This in opposition with a quasi-static elastic calculation, where this deformation would be proportional to the bending stiffness (in this case, this would be a maximum difference $1.5^{3}=3.4$ ). It is also noted that the most common used criterion for structural collapse is when the maximum deflection exceeds the wall thickness, Wei and Stewart [10], meaning that the wall with a minimum thickness of $250 \mathrm{~mm}$ would be required for the present load. Again, it is noted no changes could be found in the damage mechanism, so the results are not shown. 


\section{Conclusion}

The present study aims at developing a rate dependent dynamic interface model for the numerical simulation of masonry structures using a micro-modeling approach. The 3D interface model is implemented as a user-defined subroutine in the finite element code ABAQUS. The adequacy of the material model to replicate measured dynamic increase factors measures experimentally is demonstrated by applying various uniaxial loading conditions. A comparison between numerical predictions and field test data of two full scale masonry walls is carried out, including displacement-time response diagrams and failure mechanisms. It can be inferred from the numerical results that the model can predict the maximum deflection and failure mode over the entire length of the walls, with good agreement. Finally, a sensitivity analysis is conducted to evaluate the influence of the material properties of the joint and wall thickness on response of the walls. It is concluded that the influence of tensile strength on the maximum displacement-time response of the walls is significant, much more than the cohesion. Regarding to dilatancy angle, it is noted that the use of a zero dilatancy in case of a localized impact load leads to localized failure with shear sliding between the blocks, making it not recommended for applications. Finally, it was found that the increasing the wall thickness can decrease the maximum deflection, as expected, but the changes obtained for fast impact are significantly different than the changes in stiffness obtained in a linear elastic calculation.

\section{References}

[1] R. Varma, C. Tomar, S. Parkash, V. Sethi, Damage to Brick Masonry Panel Walls Under High Explosive Detonations, ASME-PUBLICATIONS-PVP, 351 (1996) 207-216.

[2] J.T. Baylot, B. Bullock, T.R. Slawson, S.C. Woodson, Blast response of lightly attached concrete masonry unit walls, Journal of structural engineering, 131 (2005) 1186-1193.

[3] S.T. Dennis, J.T. Baylot, S.C. Woodson, Response of 1/4-scale concrete masonry unit (CMU) walls to blast, Journal of engineering mechanics, 128 (2002) 134-142. 
[4] M. Gilbert, B. Hobbs, T. Molyneaux, The performance of unreinforced masonry walls subjected to low-velocity impacts: experiments, International Journal of Impact Engineering, 27 (2002) 231-251.

[5] C.D. Eamon, J.T. Baylot, J.L. O'Daniel, Modeling concrete masonry walls subjected to explosive loads, Journal of engineering mechanics, 130 (2004) 1098-1106.

[6] L.C. Muszynski, M.R. Purcell, Use of composite reinforcement to strengthen concrete and air-entrained concrete masonry walls against air blast, Journal of Composites for Construction, 7 (2003) 98-108.

[7] J.S. Davidson, J.R. Porter, R.J. Dinan, M.I. Hammons, J.D. Connell, Explosive testing of polymer retrofit masonry walls, Journal of Performance of Constructed Facilities, 18 (2004) 100-106.

[8] P. Lourenço, Computational strategies for masonry structures, (1996).

[9] P.B. Lourenco, G. Milani, A. Tralli, A. Zucchini, Analysis of masonry structures: review of and recent trends in homogenization techniques This article is one of a selection of papers published in this Special Issue on Masonry, Canadian Journal of Civil Engineering, 34 (2007) $1443-1457$.

[10] X. Wei, M.G. Stewart, Model validation and parametric study on the blast response of unreinforced brick masonry walls, International Journal of Impact Engineering, 37 (2010) 1150-1159.

[11] C.D. Eamon, Reliability of concrete masonry unit walls subjected to explosive loads, Journal of structural engineering, 133 (2007) 935-944.

[12] G. Milani, P.B. Lourenço, A. Tralli, Homogenized rigid-plastic model for masonry walls subjected to impact, International Journal of Solids and Structures, 46 (2009) 4133-4149.

[13] X. Wei, H. Hao, Numerical derivation of homogenized dynamic masonry material properties with strain rate effects, International Journal of Impact Engineering, 36 (2009) 522-536.

[14] H. Hao, B. Tarasov, Experimental study of dynamic material properties of clay brick and mortar at different strain rates, Australian Journal of Structural Engineering, 8 (2008) 117. 


\section{List of figures}

Fig. 1. 3D Failure envelope of the interface cap model [8]...............................................21

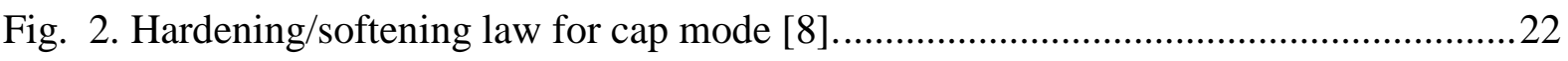

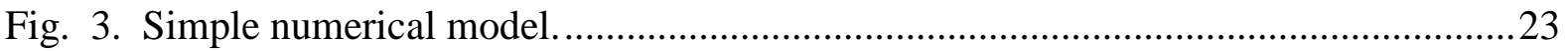

Fig. 4. Uniaxial tensile behavior of joint at different strain rate..........................................24

Fig. 5. Pure shear behavior of joint at different strain rate. .................................................25

Fig. 6. Uniaxial compressive behavior of joint at different strain rate. ...............................26

Fig. 7. Geometry of masonry parapet subjected to low velocity impact [4]..........................27

Fig. 8. Typology of dynamic load applied to: (a) URP1; (b) URP2 ....................................28

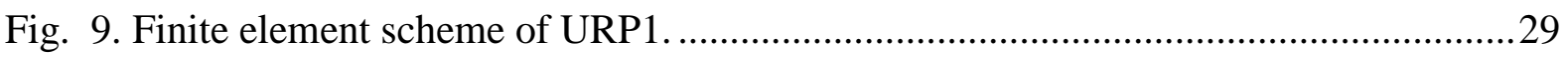

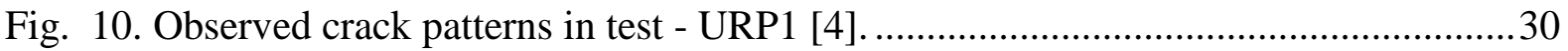

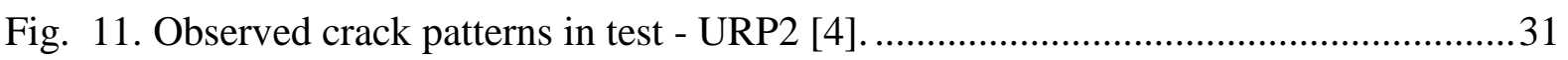

Fig. 12. Deformation of URP1 at maximum deflection: perspective (left), side view (right).

Fig. 13. Deformation of URP2 at maximum deflection: perspective (left), side view (right).

Fig. 14. Displacement vs. time response of the wall: (a) URP1; (b) URP2............................34

Fig. 15. Displacement vs. time responses of the wall URP1 with three different types of tensile strength.

Fig. 16. Displacement vs. time responses of the wall URP1 with three different types of cohesion.

Fig. 17. Displacement vs. time responses of the wall URP1 with three different types of dilatancy angle.

Fig. 18. 3D view of deformation of URP1 at maximum deflection with three different dilatancy angle: (a) $\tan \psi=0$; (b) $\tan \psi=0.1$; (c) $\tan \psi=0.2$ .38

Fig. 19. Displacement vs. time responses of the wall URP1 with three wall thicknesses: $\mathrm{t}=200 \mathrm{~mm}$; $\mathrm{t}=250 \mathrm{~mm}$; $\mathrm{t}=300 \mathrm{~mm}$

\section{List of tables}

Table 1. Material properties of joints and corresponding DIFs [14] ...................................40

Table 2. Material properties of the blocks and DIFs [4, 14] ................................................4

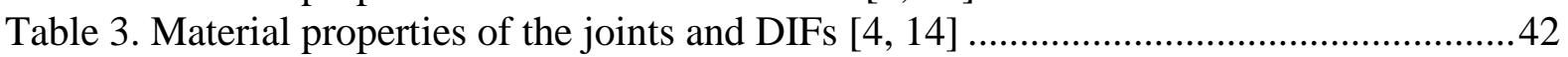

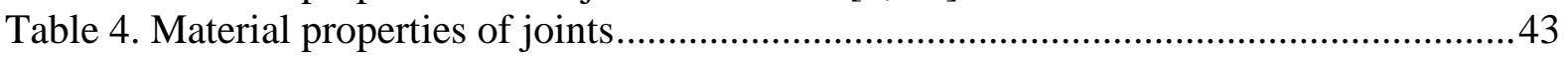




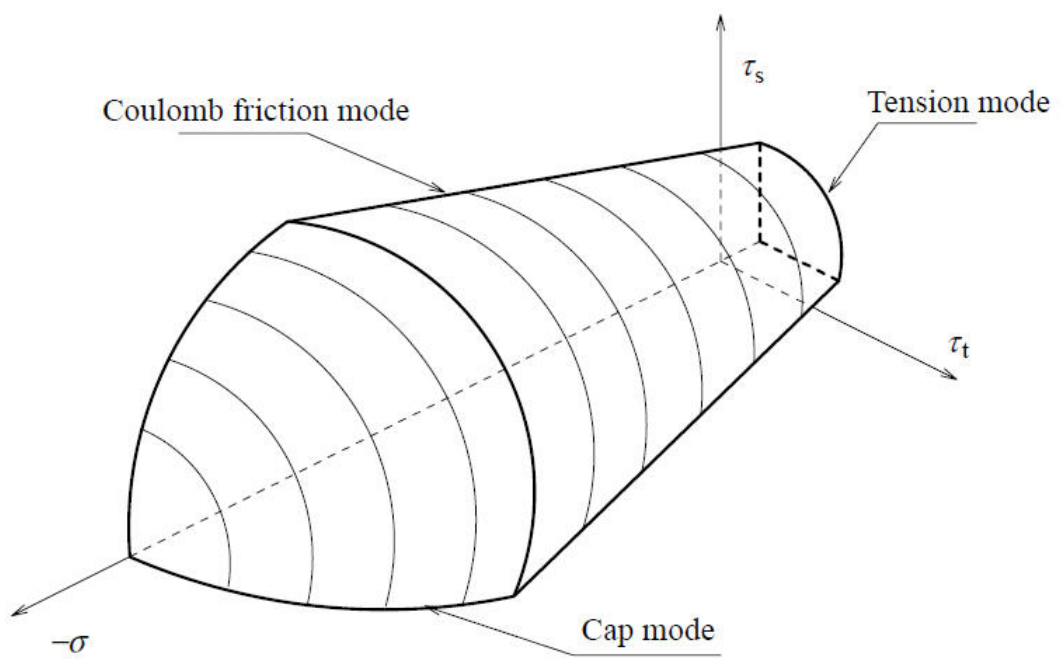

Fig. 1. 3D Failure envelope of the interface cap model [8]. 


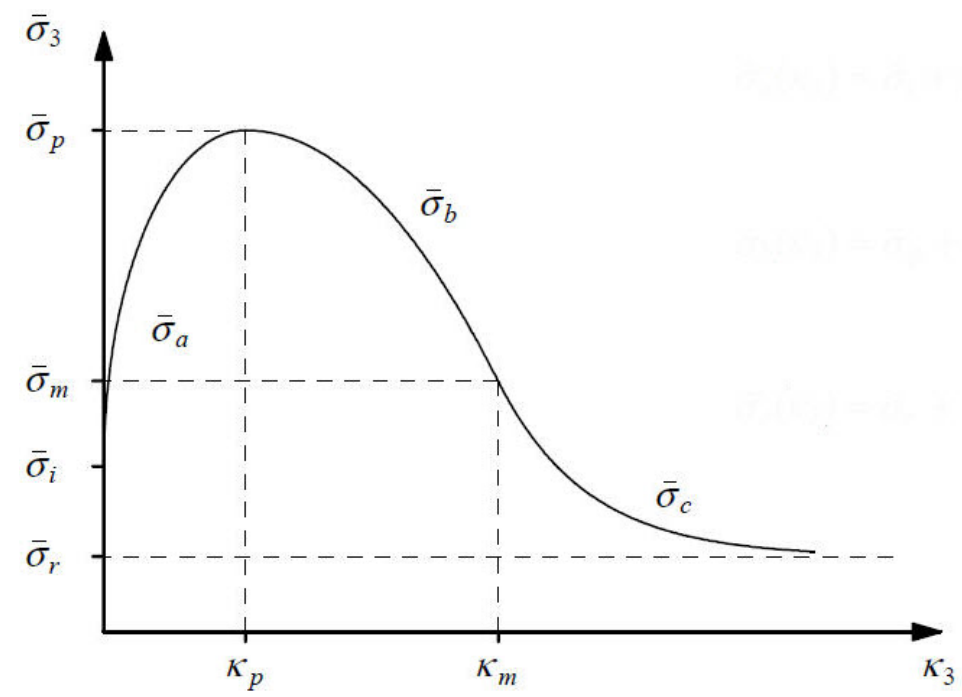

Fig. 2. Hardening/softening law for cap mode [8]. 


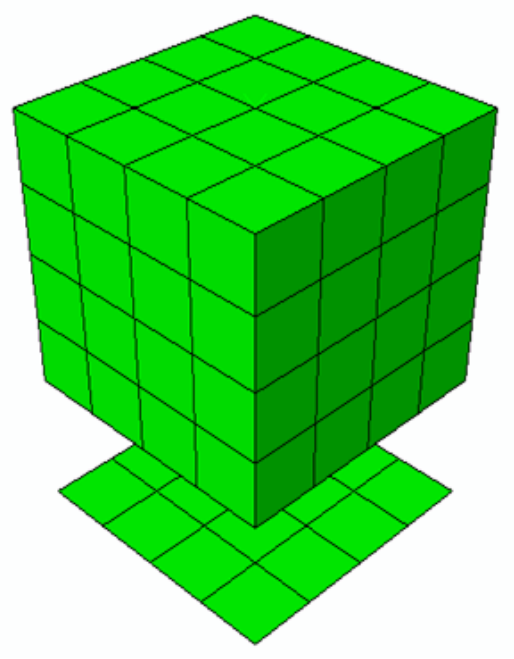

Fig. 3. Simple numerical model. 


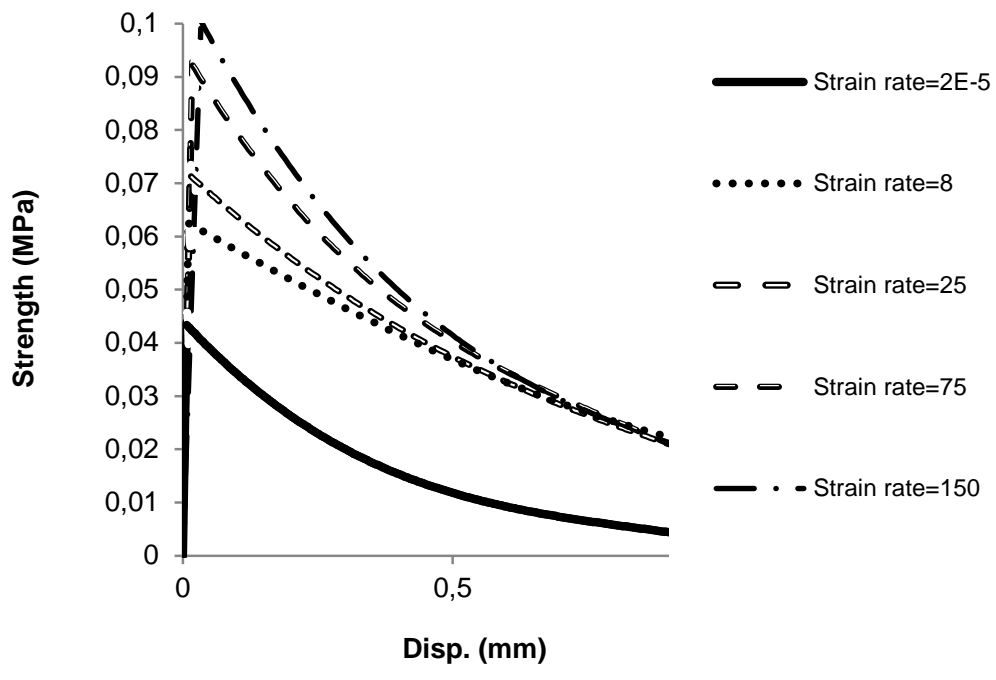

Fig. 4. Uniaxial tensile behavior of joint at different strain rate. 


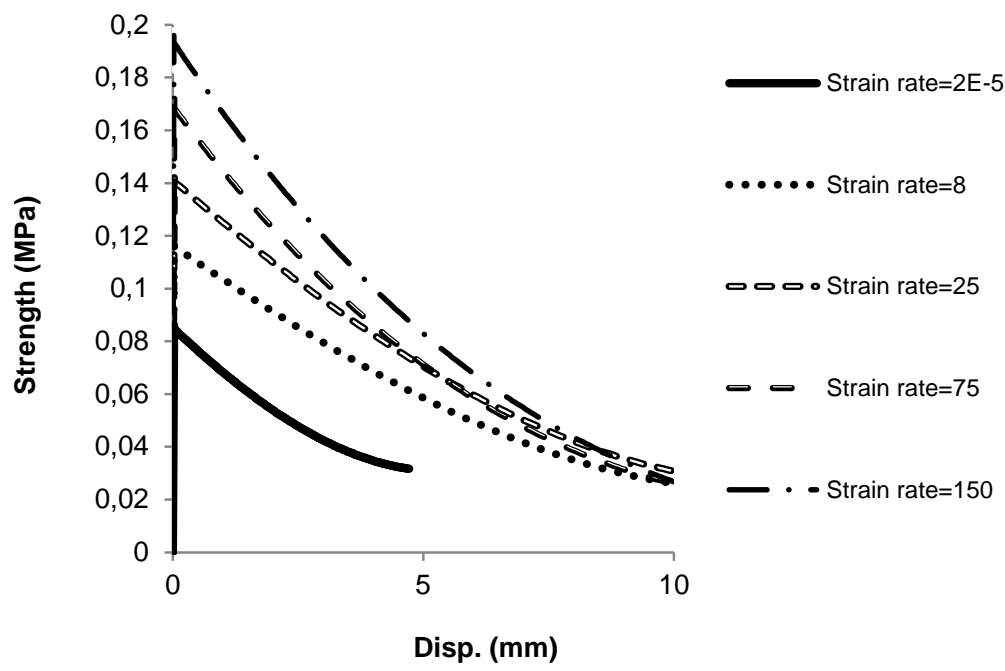

Fig. 5. Pure shear behavior of joint at different strain rate. 


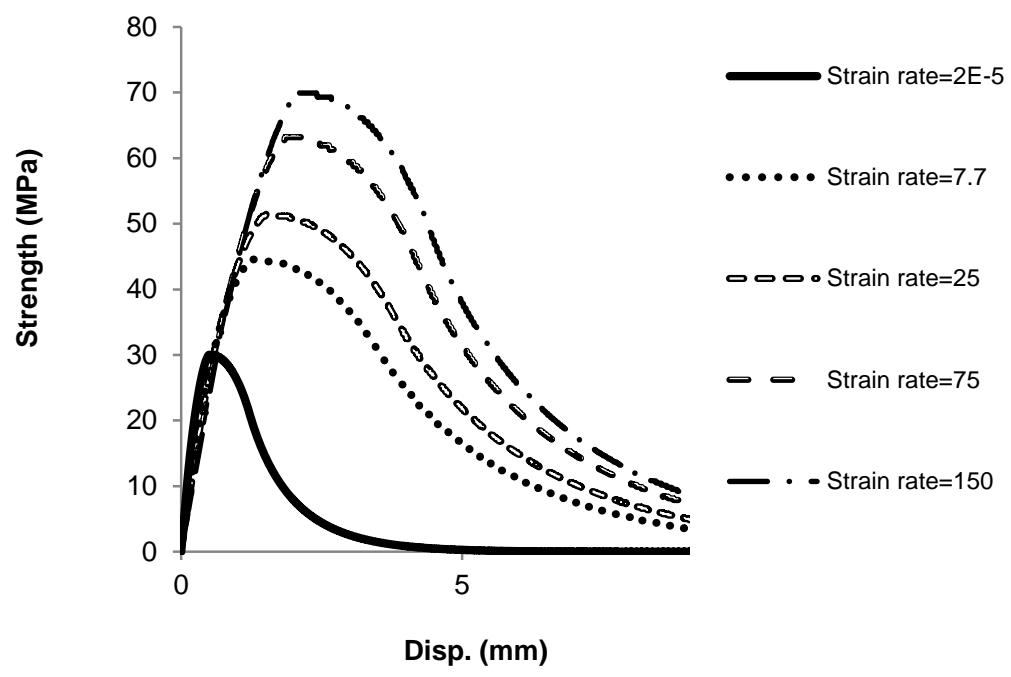

Fig. 6. Uniaxial compressive behavior of joint at different strain rate. 


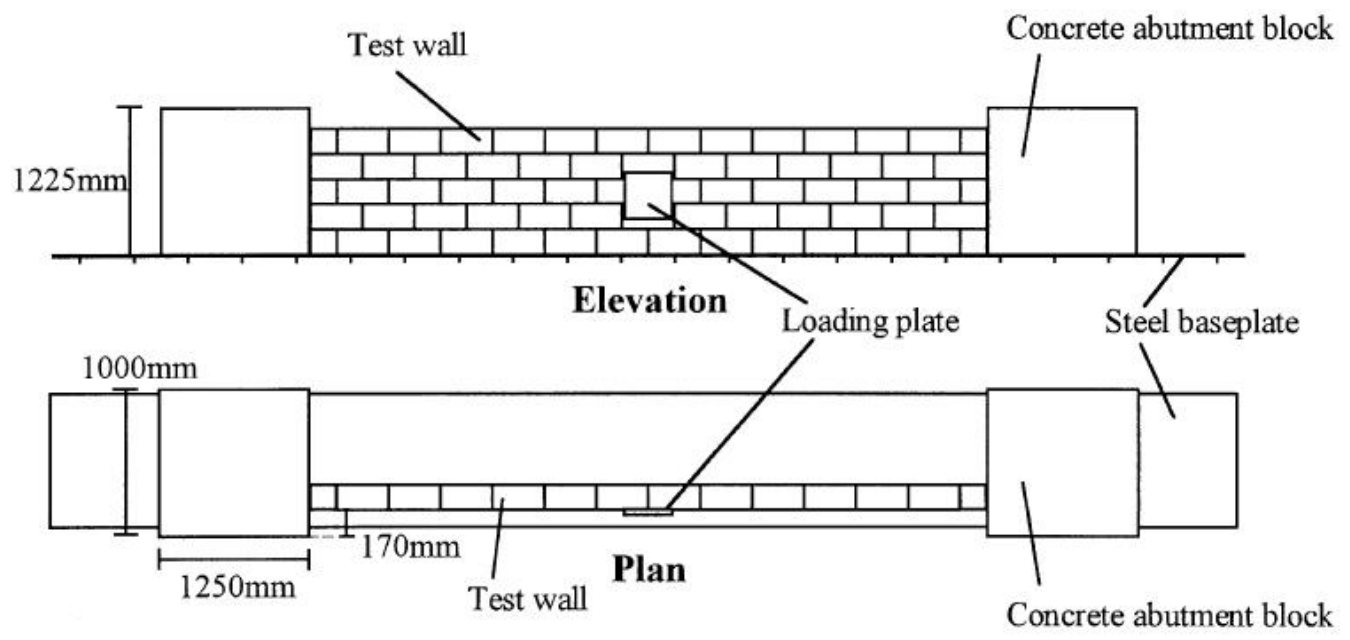

Fig. 7. Geometry of masonry parapet subjected to low velocity impact [4]. 


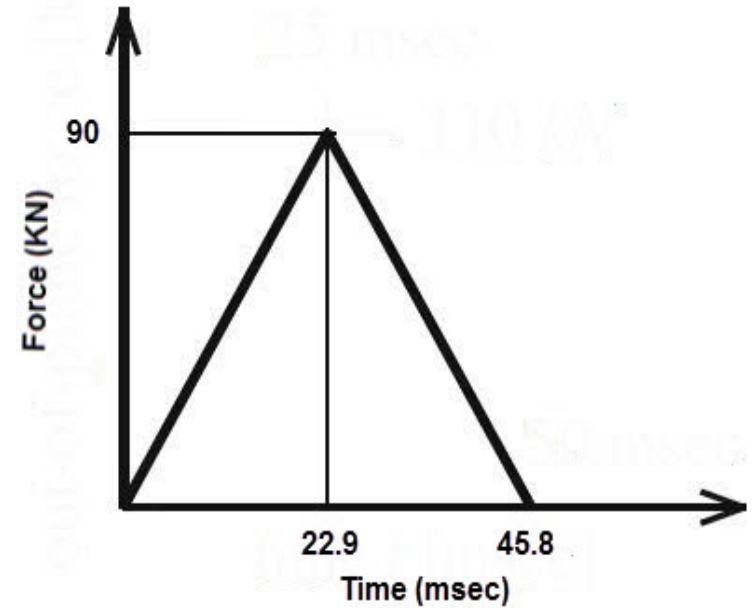

(a)

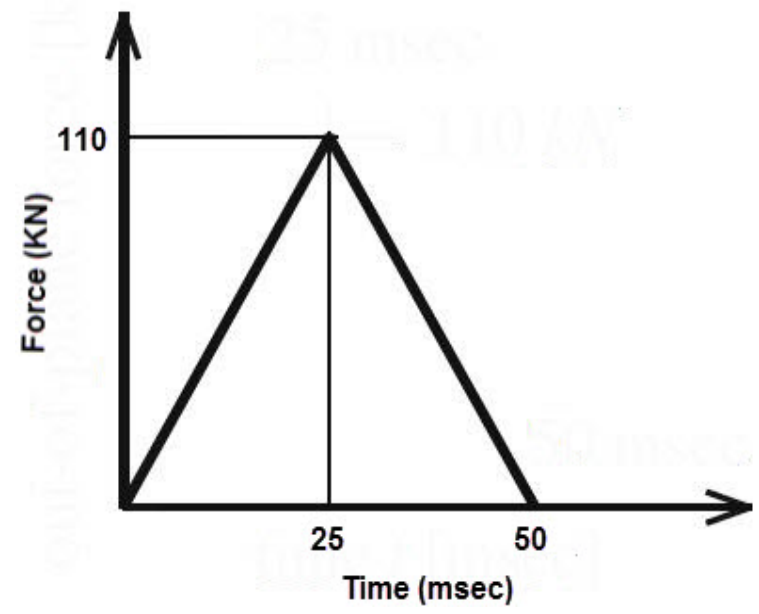

(b)

Fig. 8. Typology of dynamic load applied to: (a) URP1; (b) URP2. 


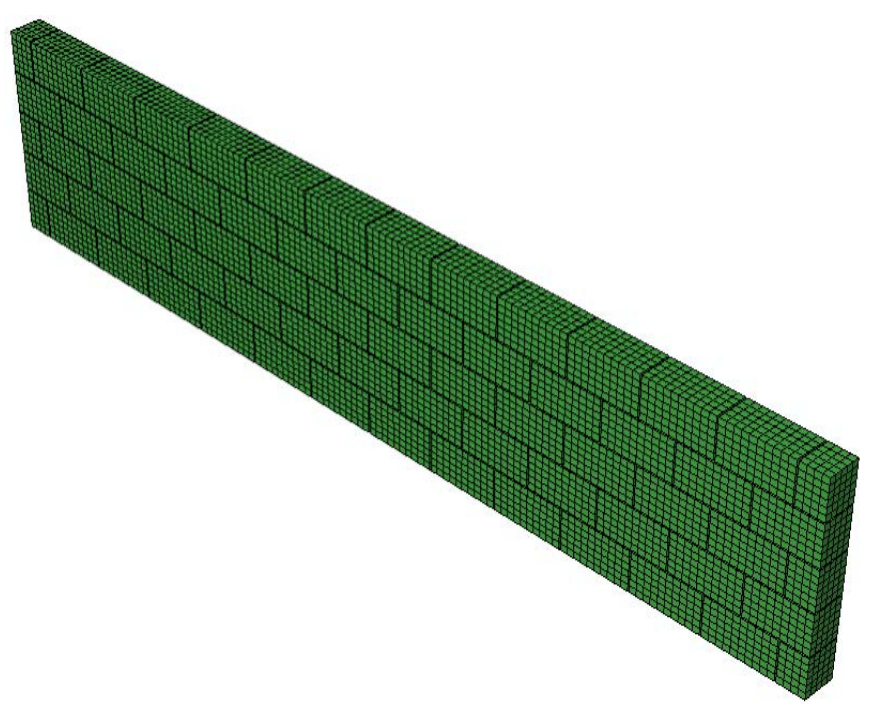

Fig. 9. Adopted finite element scheme (URP1 is shown). 


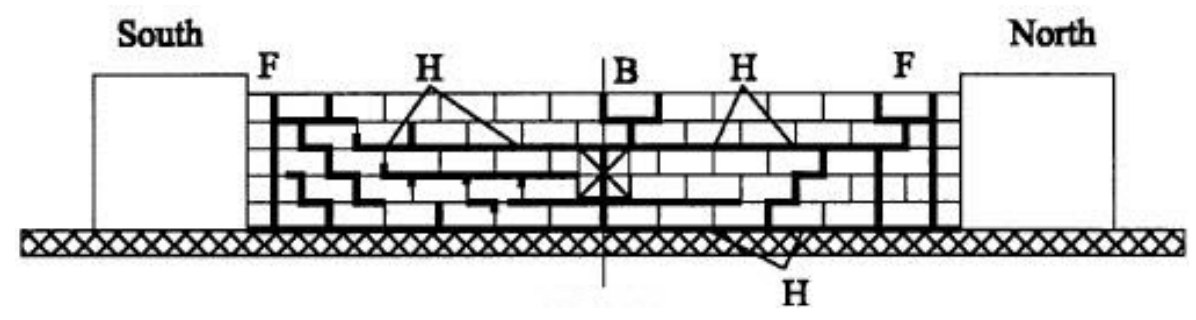

Fig. 10. Observed crack patterns in test - URP1 [4]. 


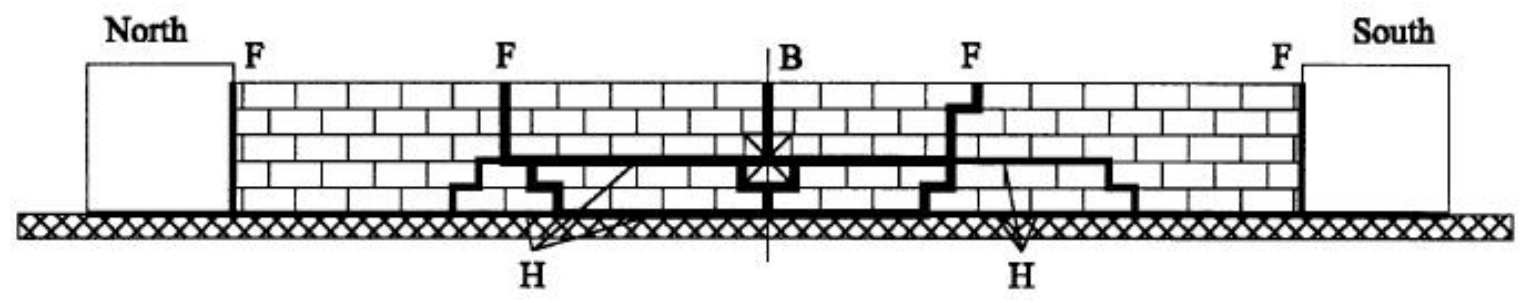

Fig. 11. Observed crack patterns in test - URP2 [4]. 

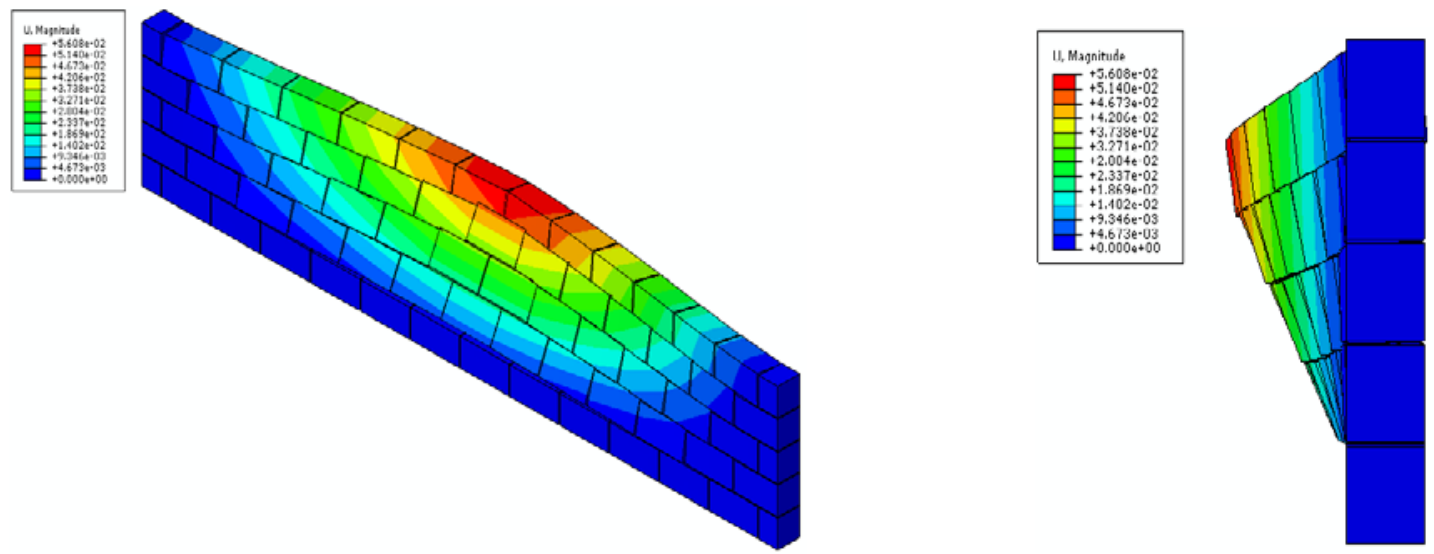

Fig. 12. Deformation of URP1 at maximum deflection: perspective (left), side view (right). 

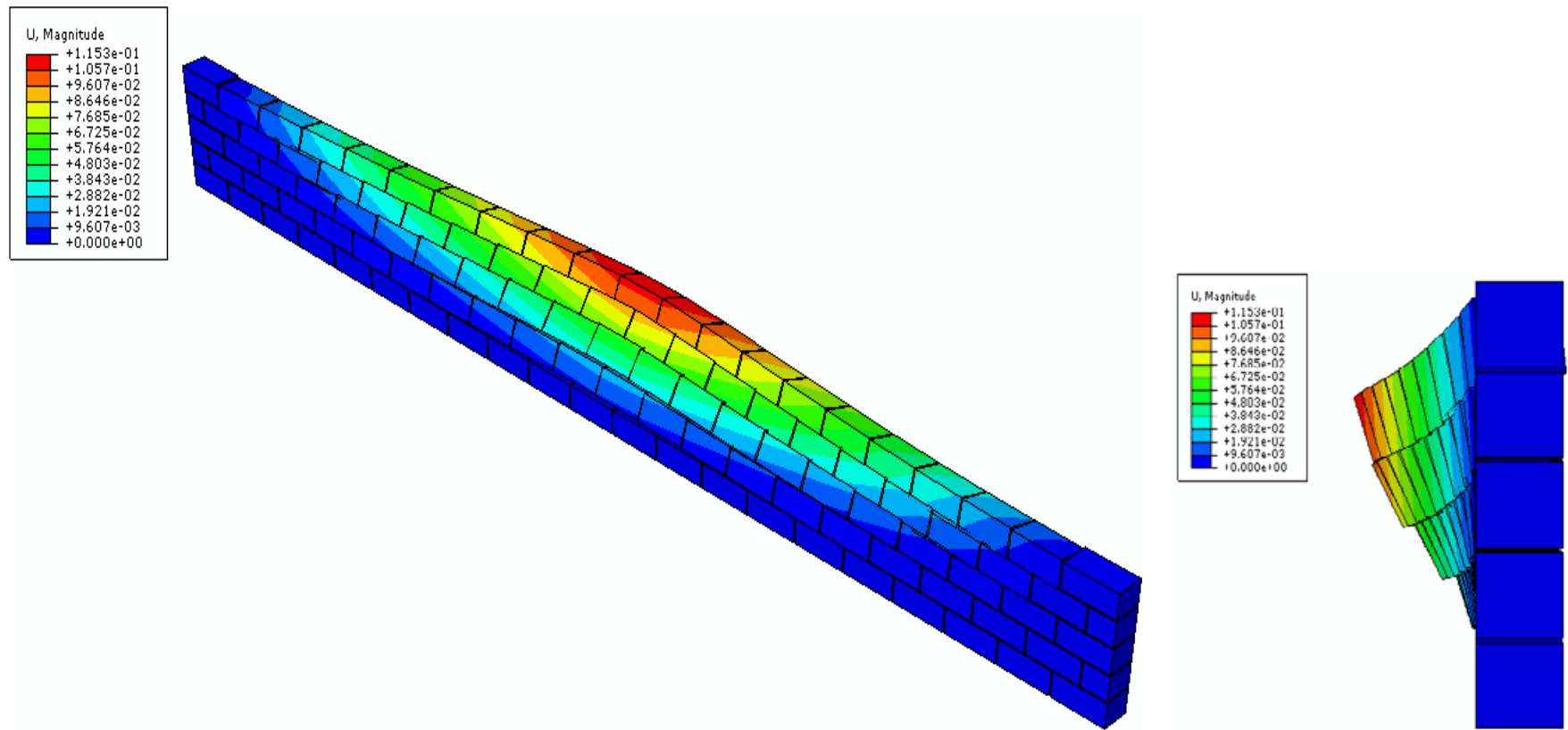

Fig. 13. Deformation of URP2 at maximum deflection: perspective (left), side view (right). 


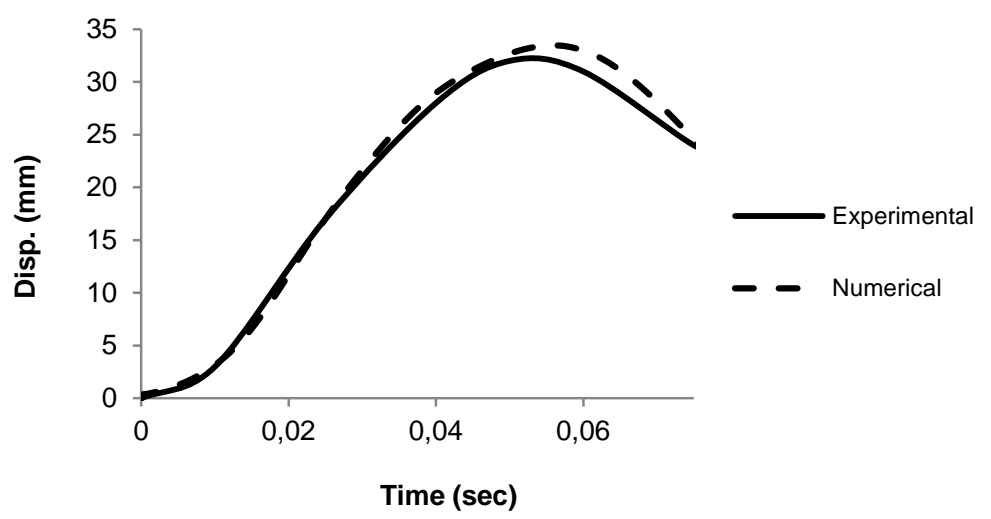

(a)

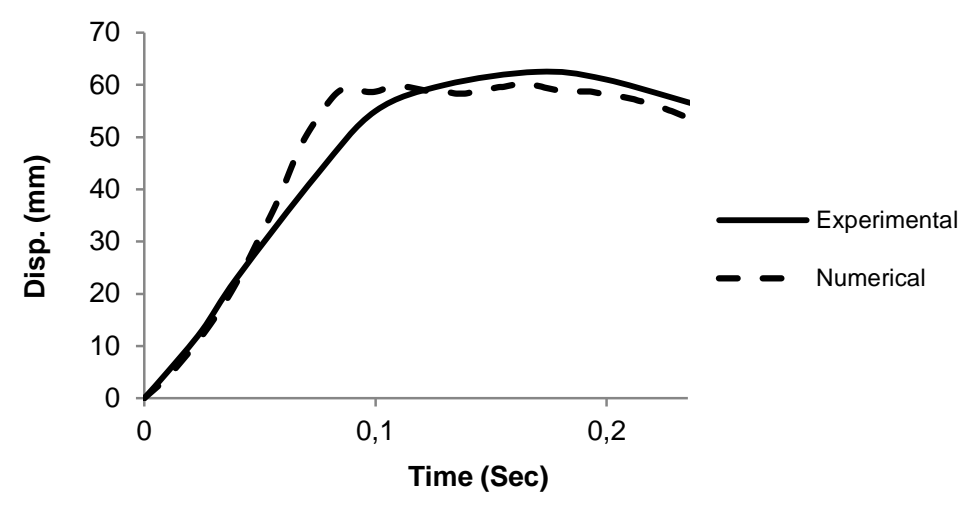

(b)

Fig. 14. Displacement vs. time response of the wall: (a) URP1; (b) URP2. 


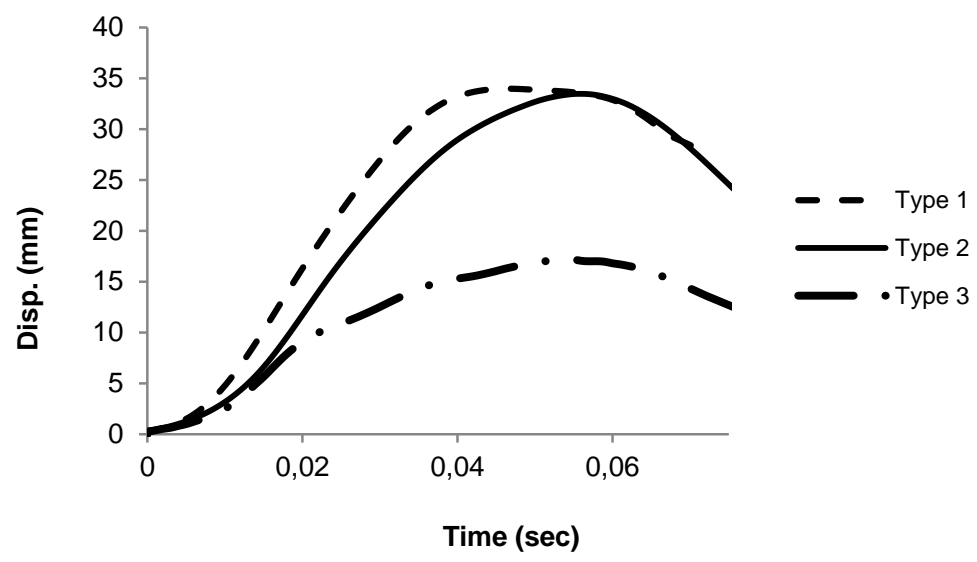

Fig. 15. Displacement vs. time responses of the wall URP1 with three different types of tensile strength. 


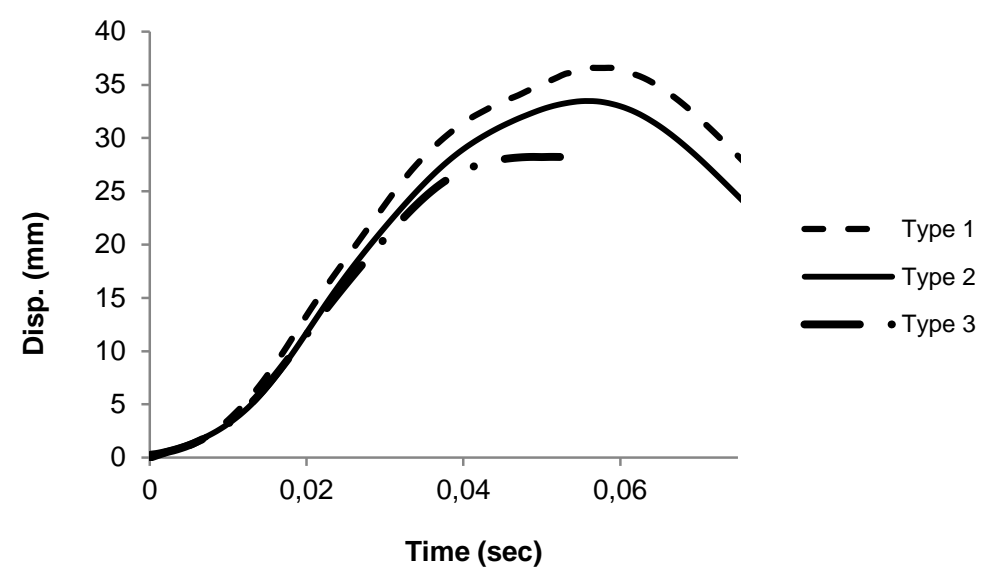

Fig. 16. Displacement vs. time responses of the wall URP1 with three different types of cohesion. 


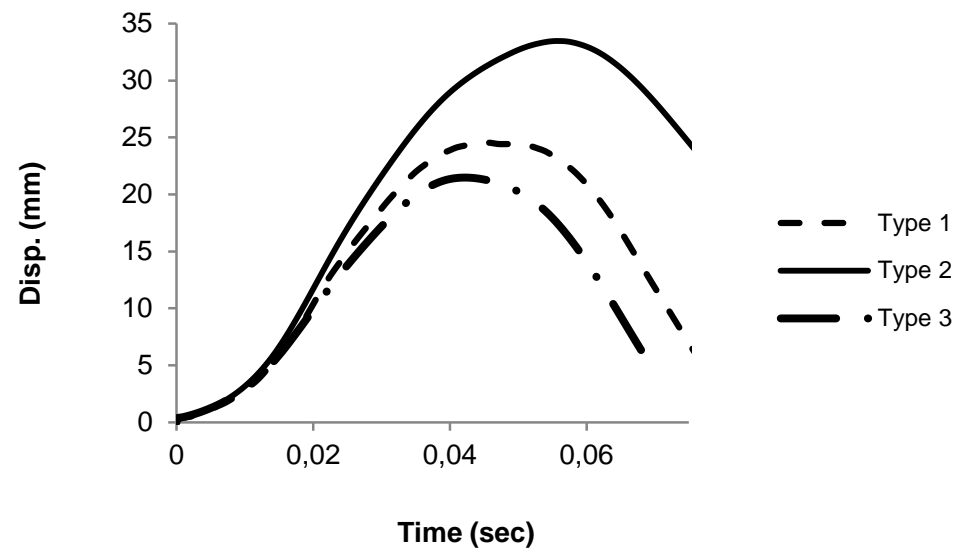

Fig. 17. Displacement vs. time responses of the wall URP1 with three different types of dilatancy angle. 


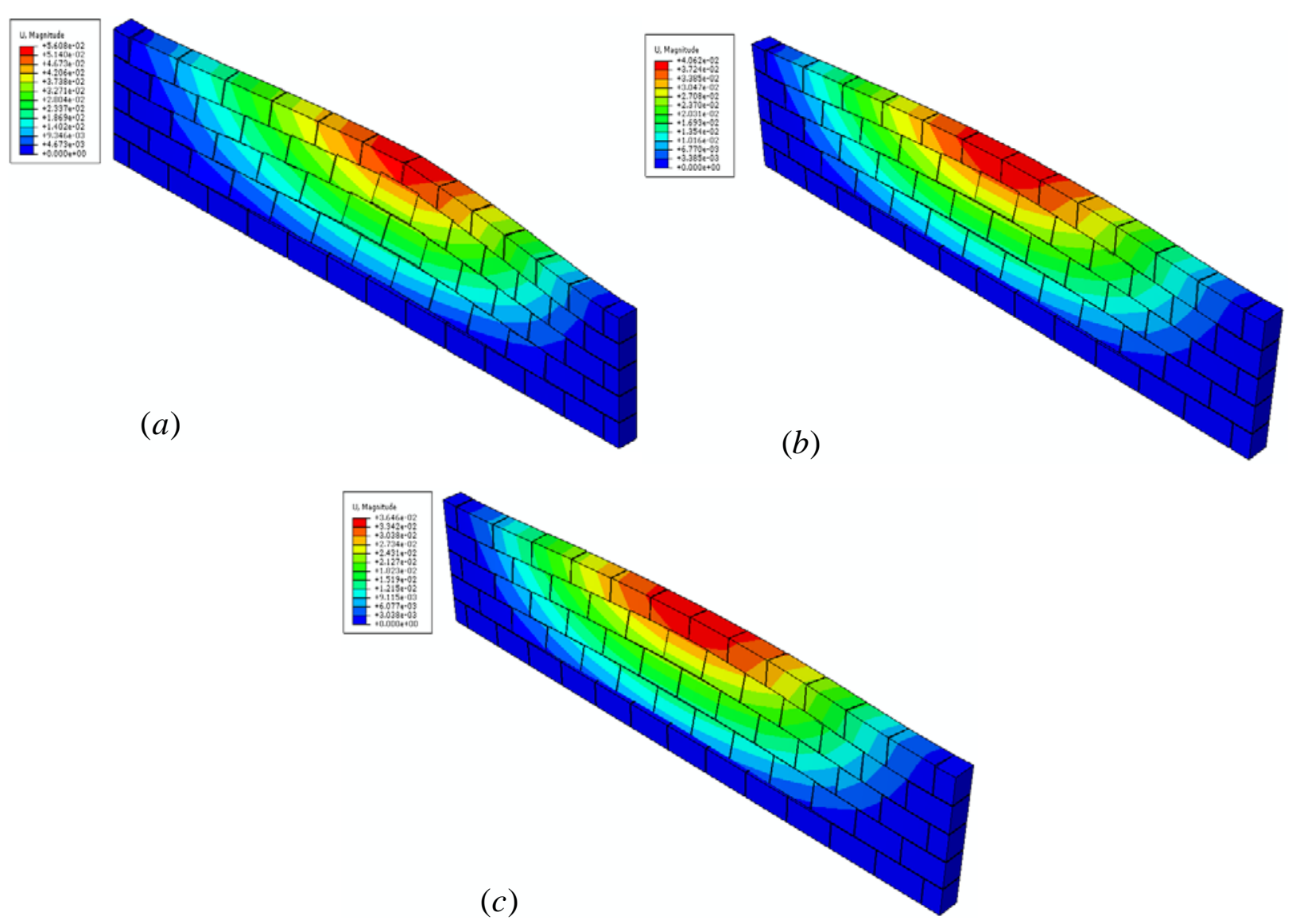

Fig. 18. 3D view of deformation of URP1 at maximum deflection with three different dilatancy angle: (a) $\tan \psi=0$; (b) $\tan \psi=0.1$; (c) $\tan \psi=0.2$. 


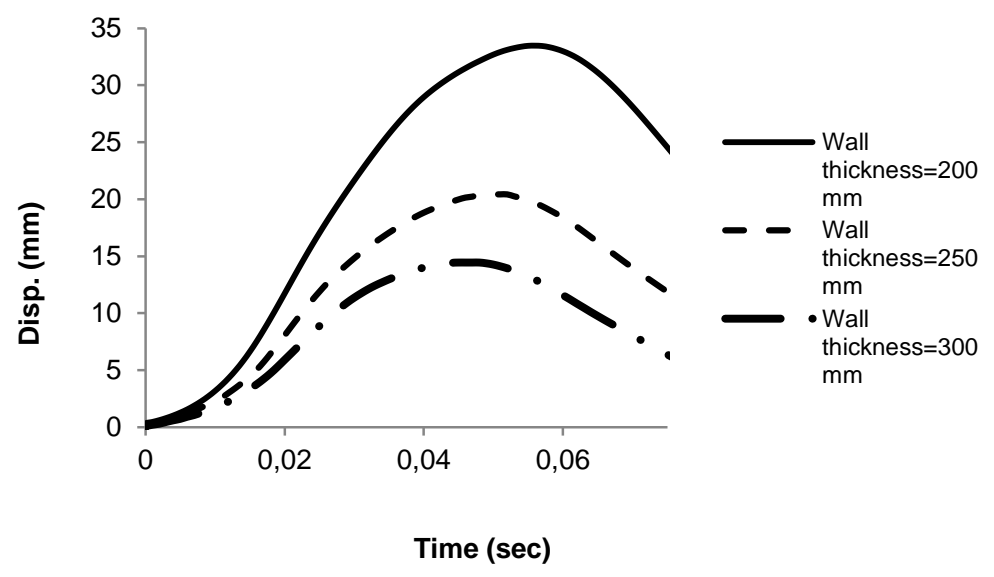

Fig. 19. Displacement vs. time responses of the wall URP1 with three wall thicknesses: $t=200 \mathrm{~mm}$; $t=250 \mathrm{~mm}$; $\mathrm{t}=300 \mathrm{~mm}$. 
Table 1

Material properties of joints and corresponding DIFs [14].

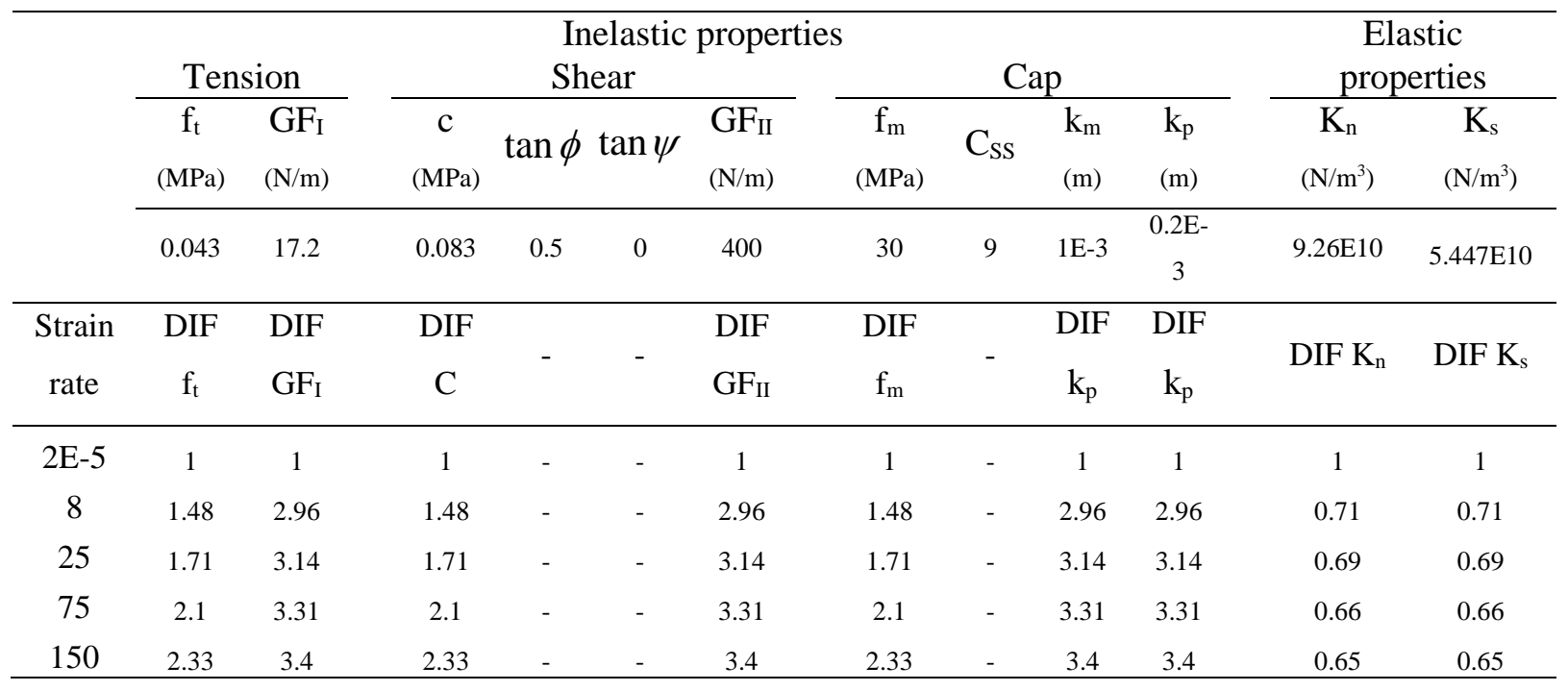


Table 2

Material properties of the blocks and DIFs [4, 14].

\begin{tabular}{ccccc}
\hline \multicolumn{2}{c}{ Weak concrete block } & & \multicolumn{2}{c}{ Strong concrete block } \\
\cline { 1 - 2 } \cline { 5 - 5 } $\mathrm{E}\left(\mathrm{N} / \mathrm{m}^{2}\right)$ & $v$ & & $\mathrm{E}\left(\mathrm{N} / \mathrm{m}^{2}\right)$ & $v$ \\
\hline $1.65 \mathrm{E} 10$ & 0.2 & & $2.88 \mathrm{E} 10$ & 0.2 \\
\hline DIF E & DIF $v$ & & DIF E & DIF $v$ \\
\hline 1.74 & 1.15 & & 1.74 & 1.15 \\
\hline
\end{tabular}


Table 3

Material properties of the joints and DIFs $[4,14]$.

\begin{tabular}{|c|c|c|c|c|c|c|c|c|c|c|c|}
\hline \multicolumn{10}{|c|}{ Inelastic properties } & \multirow{2}{*}{\multicolumn{2}{|c|}{ Elastic properties }} \\
\hline \multicolumn{2}{|c|}{ Tension } & \multicolumn{4}{|c|}{ Shear } & \multicolumn{4}{|c|}{ Cap } & & \\
\hline $\begin{array}{c}\mathrm{f}_{\mathrm{t}} \\
(\mathrm{MPa})\end{array}$ & $\begin{array}{l}\mathrm{GF}_{\mathrm{I}} \\
(\mathrm{N} / \mathrm{m})\end{array}$ & C (MPa) & $\tan \phi$ & $\tan \psi$ & $\begin{array}{l}\mathrm{GF}_{\mathrm{II}} \\
(\mathrm{N} / \mathrm{m})\end{array}$ & $\mathrm{f}_{\mathrm{m}}(\mathrm{MPa})$ & $\mathrm{C}_{\mathrm{SS}}$ & $\mathrm{k}_{\mathrm{m}}(\mathrm{m})$ & $\mathrm{k}_{\mathrm{p}}(\mathrm{m})$ & $\mathrm{K}_{\mathrm{n}}\left(\mathrm{N} / \mathrm{m}^{3}\right)$ & $\mathrm{K}_{\mathrm{s}}\left(\mathrm{N} / \mathrm{m}^{3}\right)$ \\
\hline 0.043 & 17.2 & 0.083 & 0.5 & 0 & 400 & 8.6 & 9 & $0.3 \mathrm{E}-3$ & $0.06 \mathrm{E}-3$ & $9.26 \mathrm{E} 10$ & $5.447 \mathrm{E} 10$ \\
\hline $\operatorname{DIF~}_{\mathrm{t}}$ & $\begin{array}{l}\text { DIF } \\
\text { GF }_{I}\end{array}$ & DIF c & - & - & $\begin{array}{l}\text { DIF } \\
\text { GF }_{\text {II }}\end{array}$ & DIF $f_{m}$ & - & $\begin{array}{c}\text { DIF } \\
k_{p}\end{array}$ & $\begin{array}{c}\text { DIF } \\
k_{p}\end{array}$ & DIF $K_{n}$ & DIF $K_{s}$ \\
\hline 2.1 & 3.31 & 2.1 & - & - & 3.31 & 2.1 & - & 3.31 & 3.31 & 0.66 & 0.66 \\
\hline
\end{tabular}


Table 4

Material properties of joints.

\begin{tabular}{cccc}
\hline Material parameter & Type 1 & Type 2 & Type 3 \\
\hline f $(\mathrm{MPa})$ & 0.011 & 0.043 & 0.172 \\
\hline Material parameter & Type 1 & Type 2 & Type 3 \\
\hline$C$ (MPa) & 0.021 & 0.083 & 0.332 \\
\hline Material parameter & Type 1 & Type 2 & Type 3 \\
\hline $\tan \psi$ & 0.1 & 0 & 0.2 \\
\hline
\end{tabular}

